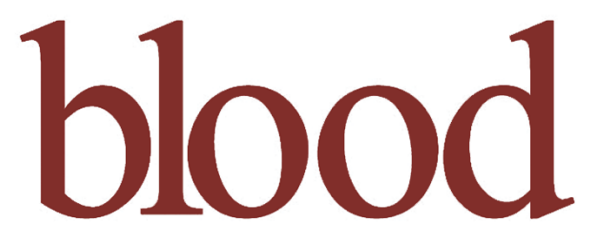

2005 105: 4635-4641

Prepublished online Feb 10, 2005;

doi:10.1182/blood-2004-06-2098

\title{
Platelet activation in cystic fibrosis
}

Brian P. O'Sullivan, Matthew D. Linden, Andrew L. Frelinger, III, Marc R. Barnard, Michele Spencer-Manzon, James E. Morris, Raneem O. Salem, Michael Laposata and Alan D. Michelson

Updated information and services can be found at:

http://bloodjournal.hematologylibrary.org/cgi/content/full/105/12/4635

Articles on similar topics may be found in the following Blood collections:

Signal Transduction (1920 articles)

Hemostasis, Thrombosis, and Vascular Biology (2358 articles)

Information about reproducing this article in parts or in its entirety may be found online at:

http://bloodjournal.hematologylibrary.org/misc/rights.dtl\#repub_requests

Information about ordering reprints may be found online at:

http://bloodjournal.hematologylibrary.org/misc/rights.dtl\#reprints

Information about subscriptions and ASH membership may be found online at:

http://bloodjournal.hematologylibrary.org/subscriptions/index.dtl

Blood (print ISSN 0006-4971, online ISSN 1528-0020), is published semimonthly by the American Society of Hematology, 1900 M St, NW, Suite 200, Washington DC 20036.

Copyright 2007 by The American Society of Hematology; all rights reserved.

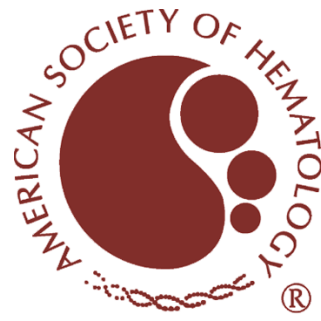




\title{
Platelet activation in cystic fibrosis
}

Brian P. O'Sullivan, Matthew D. Linden, Andrew L. Frelinger III, Marc R. Barnard, Michele Spencer-Manzon, James E. Morris, Raneem O. Salem, Michael Laposata, and Alan D. Michelson

\begin{abstract}
Cystic fibrosis (CF) is caused by a mutation of the gene encoding the cystic fibrosis transmembrane conductance regulator (CFTR). We examined platelet function in CF patients because lung inflammation is part of this disease and platelets contribute to inflammation. CF patients had increased circulating leukocyte-platelet aggregates and increased platelet responsiveness to agonists compared with healthy controls. CF plasma caused activation of normal and CF platelets; however, activation was greater in CF platelets. Furthermore,
\end{abstract}

washed CF platelets also showed increased reactivity to agonists. CF platelet hyperreactivity was incompletely inhibited by prostaglandin $\mathrm{E}_{1}\left(\mathrm{PGE}_{1}\right)$. As demonstrated by Western blotting and reverse-transcriptase-polymerase chain reaction (RT-PCR), there was neither CFTR nor CFTR-specific mRNA in normal platelets. There were abnormalities in the fatty acid composition of membrane fractions of CF platelets. In summary, CF patients have an increase in circulating activated platelets and platelet reactivity, as determined by mono- cyte-platelet aggregation, neutrophilplatelet aggregation, and platelet surface P-selectin. This increased platelet activation in CF is the result of both a plasma factor(s) and an intrinsic platelet mechanism via cyclic adenosine monophosphate (cAMP)/adenylate cyclase, but not via platelet CFTR. Our findings may account, at least in part, for the beneficial effects of ibuprofen in CF. (Blood. 2005;105:4635-4641)

() 2005 by The American Society of Hematology

\section{Introduction}

Cystic fibrosis (CF) is the most common lethal genetic disease in whites, affecting approximately 1 in 2500 live births. ${ }^{1}$ In 1989 , Kerem et $\mathrm{al}^{2}$; Riordan et $\mathrm{al}^{3}$; and Rommens et $\mathrm{al}^{4}$ identified the genetic mutation responsible for $\mathrm{CF}$ and cloned its protein product, which is called the cystic fibrosis transmembrane conductance regulator (CFTR). CFTR is a member of the adenosine triphosphate (ATP)-binding cassette family of transporters and acts chiefly as a chloride channel, although it has various other functions including regulation of alternate chloride channels and epithelial sodium channels, and transport of ATP. ${ }^{5-7}$

Defects in CFTR cause reduced chloride secretion into airways and enhanced sodium reabsorption, thereby resulting in dehydrated airway secretions, poor mucociliary clearance, and airway obstruction. ${ }^{1}$ Obstruction of the airways, along with poorly understood altered host defense mechanisms and an enhanced inflammatory response, leads to chronic airway infection and inflammation. This, in turn, causes an influx of polymorphonuclear cells that, when they become senescent and release their DNA into the airway mucous, contribute to thickening of airway secretions. ${ }^{8}$ The self-perpetuating cycle of obstruction, infection, and inflammation eventually causes pulmonary parenchymal destruction and respiratory failure. The life expectancy for CF patients in the United States is currently approximately 33 years. ${ }^{9}$

Previous studies have shown that CF patients have increased ex vivo platelet aggregability, increased release of thromboxane $A_{2}$
$\left(\mathrm{TXA}_{2}\right),{ }^{10-12}$ and a blunted response to prostaglandin $\mathrm{E}_{1}\left(\mathrm{PGE}_{1}\right)$ induced inhibition of platelet aggregation. ${ }^{13,14}$ Platelets contain or generate many inflammatory mediators including $\mathrm{TXA}_{2}$, platelet activating factor (PAF), RANTES (regulated upon activation, normal T-cell expressed and presumably secreted), histamine, serotonin, soluble CD40 ligand (sCD40L), and growth factors. ${ }^{15}$ These mediators are released upon platelet activation and have been associated with inflammatory lung disease in asthma. ${ }^{16}$ Therefore, endogenous platelet activation with release of proinflammatory mediators could play an important role in the pathogenesis of CF lung disease, and a greater understanding of this mechanism could lead to novel clinical interventions. Significantly, antiinflammatory agents known to inhibit production and release of platelet-derived inflammatory mediators slow the progression of lung disease in $\mathrm{CF} .{ }^{17}$

In this study, we attempted to further elucidate platelet function in $\mathrm{CF}$ and to determine if the abnormalities were due to a plasma factor or were an intrinsic property of CF platelets. In addition, we looked for both CFTR protein and CFTR mRNA in platelets to determine whether the underlying $\mathrm{CF}$ defect in chloride channel function could account for the platelet abnormalities. Finally, lipid fractions of CF and control platelets were examined because we have previously demonstrated that CFTRexpressing tissue from patients with $\mathrm{CF}$ has an imbalance in long-chain polyunsaturated fatty acids with an excess of arachidonic acid (AA, a precursor to proinflammatory mediators) and
From the Department of Pediatrics, UMass Memorial Health Care and University of Massachusetts Medical School, Worcester, MA; the Center for Platelet Function Studies, University of Massachusetts Medical School, Worcester, MA; the Department of Molecular Biology, Genzyme, Framingham, MA; and the Division of Laboratory Medicine, Department of Pathology, Massachusetts General Hospital and Harvard Medical School, Boston, MA.

Submitted June 3, 2004; accepted February 2, 2005. Prepublished online as Blood First Edition Paper, February 10, 2005; DOI 10.1182/blood-2004-06-2098.
Reprints: Brian P. O'Sullivan, Department of Pediatrics, UMass Memorial Health Care, 55 Lake Ave, North, Worcester, MA 01655; e-mail: osullivb@ummhc.org.

The publication costs of this article were defrayed in part by page charge payment. Therefore, and solely to indicate this fact, this article is hereby marked "advertisement" in accordance with 18 U.S.C. section 1734.

(C) 2005 by The American Society of Hematology 
From www.bloodjournal.org at UNIV OF MASSACHUSETTS on April 3, 2008. For personal use only.

a paucity of docosahexaenoic acid (DHA, a precursor to anti-inflammatory mediators) $;^{18}$ such a fatty acid imbalance in CF platelets could contribute to their hyperreactivity.

\section{Patients, materials, and methods}

\section{Patient enrollment}

CF patients and healthy control subjects were enrolled in this study. This study was approved by UMass Medical School's Committee for the Protection of Human Subjects in Research (institutional review board [IRB]), Worcester, MA. IRB-approved, written informed consent was obtained for all CF patients and healthy control subjects, in accordance with the Declaration of Helsinki. All CF patients included in the study met the CF Foundation Consensus Statement requirements for the diagnosis of $\mathrm{CF}^{19}$ Patients were either outpatients in their usual state of health or inpatients receiving care for an exacerbation of their $\mathrm{CF}$ (Table 1). Hospitalized patients had blood drawn within 24 to 48 hours of admission to limit treatment effect from antibiotics or diet changes. Only one patient was receiving steroid therapy at the time of the study (patient no. 11, Table 1). Clinical information regarding genotype, pulmonary function, and vitamin $E$ status of the CF patients is shown in Table 1. Neither patients nor controls ingested antiplatelet medication (including aspirin and other nonsteroidal antiinflammatory drugs [NSAIDS]) for 10 days prior to blood collection. Where appropriate, $\mathrm{ABO}$ and Rhesus $\mathrm{D}(\mathrm{RhD})$ blood groups of the control subjects were matched to the relevant $\mathrm{CF}$ patients.

\section{Comparison of circulating activated platelets and platelet reactivity between CF patients and healthy controls}

Circulating activated platelets and platelet reactivity in CF patients and healthy control subjects were compared by whole-blood flow cytometric detection of monocyte-platelet aggregates and neutrophil-platelet aggregates. ${ }^{20,21}$ Blood samples were obtained via venipuncture from CF patients $(\mathrm{n}=18)$ and healthy controls $(n=18)$ by mixing 9 parts whole blood with 1 part $0.105 \mathrm{M}(3.2 \%)$ trisodium citrate. Samples were assayed within 15 minutes. Microfuge tubes were prepared containing a mixture of HEPES-Tyrode buffer (10 mM HEPES [ $N$-2-hydroxyethylpiperazine- $N^{\prime}$-2-ethanesulfonic acid], $137 \mathrm{mM}$ sodium chloride, $2.8 \mathrm{mM}$ potassium chloride, $1 \mathrm{mM}$ magnesium chloride, $12 \mathrm{mM}$ sodium carbonate, $0.4 \mathrm{mM}$ sodium phosphate, $5.5 \mathrm{mM}$ glucose, $0.35 \% \mathrm{wt} / \mathrm{vol}$ bovine serum albumin, $\mathrm{pH}$ 7.4), fluorescein isothiocyanate (FITC)-conjugated antiCD14 (TÜK4; DAKO, Carpinteria, CA), phycoerythrin (PE)-conjugated antiCD41 (5B12; DAKO), and platelet agonist. The blood sample was added to this reaction mixture and incubated at room temperature for 15 minutes. Final concentrations of agonists in the reaction mixture were $1.5 \mu \mathrm{M}$ thrombin receptor activating peptide (TRAP), 0.5 or $20 \mu \mathrm{M}$ adenosine diphosphate (ADP), or no agonist (HEPES-Tyrode buffer). After incubation, samples were fixed and erythrocytes lysed by fluorescence-activated cell sorter (FACS) lysing solution (Becton Dickinson, Mountain View, CA). Samples were analyzed in a FACSCalibur (Becton Dickinson) flow cytometer. Monocytes and neutrophils were identified by light scatter properties and differential expression of CD14. Staining with an irrelevant PE-conjugated mouse immunoglobulin $\mathrm{G}_{1}$-phycoerythrin $\left(\mathrm{MIgG}_{1}-\mathrm{RPE}\right.$; DAKO) was used to set a marker to identify platelet $\mathrm{CD} 41^{+}$

Table 1. Clinical characteristics of cystic fibrosis patients

\begin{tabular}{|c|c|c|c|c|c|c|}
\hline Patient & Age, $y$ & $\begin{array}{l}\text { Vitamin } \mathrm{E} \\
\mathrm{mg} / \mathrm{L}^{\star}\end{array}$ & $\begin{array}{c}\mathrm{FEV}_{1}, \% \\
\text { predicted } \dagger\end{array}$ & $\begin{array}{l}\text { Inpatient or } \\
\text { outpatient‡ }\end{array}$ & Genotype & Platelet studies§ \\
\hline 1 & 20 & 6.6 & 25 & In & $\delta$ F508/unk & A \\
\hline 2 & 20 & 3.6 & 70 & In & $\delta$ F508/G542X & A \\
\hline 3 & 11 & 16.8 & 92 & Out & $\delta$ F508/dF508 & A \\
\hline 4 & 16 & 5.4 & 101 & Out & 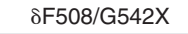 & A \\
\hline 5 & 9 & 3.9 & 124 & Out & $\delta F 508 / d F 508$ & $A, F$ \\
\hline 6 & 6 & 5.1 & 118 & Out & $\delta$ F508/dF508 & $A, F$ \\
\hline 7 & 13 & 8.1 & 119 & Out & $\delta F 508 / d F 508$ & $A, F$ \\
\hline 8 & 10 & 9.7 & 104 & Out & $\delta \mathrm{F} 508 / \mathrm{dF508}$ & $A, F$ \\
\hline 9 & 22 & 9.0 & 58 & In & $\delta$ F508/dF508 & A \\
\hline 10 & 19 & 8.0 & 57 & Out & $\delta F 508 / N 1303 \mathrm{~K}$ & A \\
\hline 11 & 17 & 7.0 & 24 & Out & $\delta F 508 / d F 508$ & $A, D, E$ \\
\hline 12 & 20 & 3.2 & 55 & Out & $\delta$ F508/dF508 & $A, D$ \\
\hline 13 & 15 & 5.8 & 41 & In & $\delta \mathrm{F} 508 / \mathrm{dF508}$ & $A, D, E$ \\
\hline 14 & 26 & 12.7 & 88 & Out & $\delta \mathrm{F508/dF508}$ & $A, D$ \\
\hline 15 & 11 & 16.3 & 72 & Out & $\delta \mathrm{F} 508 / \mathrm{W} 1282 \mathrm{X}$ & $A, D$ \\
\hline 16 & 18 & 10.0 & 58 & In & $\delta \mathrm{F} 508 / \mathrm{dF508}$ & $A, D$ \\
\hline 17 & 22 & 10.5 & 50 & Out & $\delta \mathrm{F508/dF508}$ & $A, D$ \\
\hline 18 & 35 & 8.6 & 87 & Out & $\delta \mathrm{F} 508 / \mathrm{C} 276 \mathrm{X}$ & $A, E$ \\
\hline 19 & 17 & 16.2 & 62 & In & $\delta F 508 / d F 508$ & $B, E$ \\
\hline 20 & 14 & 4.1 & 85 & In & $\delta \mathrm{F508/dF508}$ & B \\
\hline 21 & 22 & 2.3 & 62 & $\ln$ & $\delta$ F508/G542X & B \\
\hline 22 & 21 & 7.7 & 54 & In & ઈF508/N1303K & B \\
\hline 23 & 19 & 2.4 & 69 & In & $\delta F 508 / Y 1092 X$ & B \\
\hline 24 & 19 & 4.6 & 87 & In & $\delta F 508 / d F 508$ & $\mathrm{~B}, \mathrm{C}, \mathrm{E}$ \\
\hline 25 & 21 & 8.2 & 58 & In & R334W/unk & C \\
\hline 26 & 22 & 5.8 & 85 & In & $\delta \mathrm{F} 508 / \mathrm{dF} 508$ & $\mathrm{C}, \mathrm{E}$ \\
\hline 27 & 22 & 2.9 & 67 & In & unk/unk & $\mathrm{C}$ \\
\hline 28 & 20 & 6.7 & 77 & In & $\delta$ F508/dF508 & $\mathrm{E}$ \\
\hline 29 & 18 & 13.3 & 92 & In & $\delta \mathrm{F} 508 / \mathrm{dF} 508$ & E \\
\hline 30 & 22 & 8.8 & 71 & In & $\delta$ F508/394delTT & E \\
\hline 31 & 15 & 13.0 & 68 & In & $\delta$ F508/dF508 & E \\
\hline 32 & 14 & unk & 97 & Out & $\delta F 508 / d F 508$ & $\mathrm{E}$ \\
\hline
\end{tabular}

unk indicates unknown.

${ }^{*}$ Measured as alpha-tocopherol. Lower limit of normal $=5.5 \mathrm{mg} / \mathrm{L}$.

†Normal: $80 \%$ to $120 \%$ of predicted.

†Outpatients were seen for routine CF Clinic visit; inpatient were hospitalized for therapy of an exacerbation of CF.

§Studies done on each subject's platelets: A indicates leukocyte-platelet aggregates (Figure 1); B, whole blood studies (Figures 2-3); C, washed platelet-P-selectin measurements (Figure 4); D, inhibition of P-selectin expression by $\mathrm{PGE}_{1}$ (Figure 5); E, measurement of fatty acids (Figure 6); and F, AA and thromboxane release. 
leukocytes. Expression of platelet-specific CD41 on the surface of the leukocytes indicated the formation of monocyte-platelet aggregates or neutrophil-platelet aggregates. The percentage of monocyte-platelet aggregates and neutrophilplatelet aggregates in circulating blood (ie, no exogenously added agonist) and the reactivity of platelets to TRAP and ADP was compared for CF patients and healthy controls by unpaired $t$ tests.

\section{Activation and reactivity of normal donor and CF platelets by CF plasma}

To determine if platelet activation occurred secondary to a CF plasma constituent or as a result of an intrinsic CF platelet hyperreactivity, a plasma crossover experiment was conducted and platelet activation and reactivity were assessed by monocyte- and neutrophil-platelet aggregation using whole-blood flow cytometry. ${ }^{20,21}$ Blood from $\mathrm{CF}$ patients and $\mathrm{ABO}$ RhD-matched control subjects ( $n=6$ pairs) was drawn into $3.2 \%$ citrate vacuum tubes. Citrated plasma was obtained by centrifugation at $1700 \mathrm{~g}$ for 15 minutes at room temperature. Citrated whole blood $(120 \mu \mathrm{L})$ from healthy controls was incubated with $420 \mu \mathrm{L}$ normal or CF plasma and then, in a parallel experiment, $120 \mu \mathrm{L}$ citrated whole blood from CF patients was incubated with $420 \mu \mathrm{L}$ normal or $\mathrm{CF}$ plasma for 20 minutes at room temperature. In analogous experiments, $420 \mu \mathrm{L}$ normal plasma was used to resuspend Mead acid (20:3 n-9) at 3 concentrations $(1,5$, or $25 \mu \mathrm{M})$ that were then mixed with autologous whole blood $120 \mu \mathrm{L}$ and incubated for 30 minutes at room temperature to determine if incorporation of this fatty acid into non-CF platelets affected formation of heterotypic aggregates $(n=6)$. Aliquots of each mixture were added to a reaction mix consisting of FITC-conjugated anti-CD14 (TÜK4), PE-conjugated anti-CD41 (5B12), and agonist. Final concentrations of agonists in the reaction mixture were 4 or $20 \mu \mathrm{M}$ ADP, and $3 \mu \mathrm{M}$ TRAP. Samples were fixed, lysed, and analyzed for monocyte- and neutrophil platelet aggregates as described for measurement of circulating activated platelets. Matched pair-wise comparison of means for each mixture for each agonist was achieved using 2-sided, paired $t$ tests.

\section{Activation and reactivity of washed healthy donor and CF platelets}

In order to assess the activation and reactivity of CF platelets without the influence of plasma constituents, P-selectin expression on washed platelet preparations was determined by flow cytometry. ${ }^{21-24}$ Washed platelet preparations of CF patients $(n=4)$ and healthy controls $(n=4)$ were prepared using established methods. ${ }^{22,25}$ Briefly, platelet-rich plasma (PRP) was prepared by centrifugation of $3.2 \%$ citrated blood samples at $150 \mathrm{~g}$ for 15 minutes at room temperature. PRP was added to citrate wash buffer (11 $\mathrm{mM}$ glucose, $128 \mathrm{mM}$ sodium chloride, $4.3 \mathrm{mM}$ sodium phosphate monobasic, $7.5 \mathrm{mM}$ sodium phosphate, $4.8 \mathrm{mM}$ sodium citrate, $2.4 \mathrm{mM}$ citric acid, $0.35 \% \mathrm{wt} / \mathrm{vol}$ bovine serum albumin, $\mathrm{pH} 6.5$ ) containing apyrase VII (1.2 U/mL; Sigma, St Louis, MO) and PGE $_{1}(300 \mathrm{ng} / \mathrm{mL}$; Cayman Chemical, Ann Arbor, MI), and the mixture was centrifuged at $1200 \mathrm{~g}$ for 10 minutes at room temperature. The platelet pellet was resuspended in this buffer and washed twice more. The resulting platelet pellet was resuspended at $1.5 \times 10^{8} / \mathrm{mL}$ in HEPES-Tyrode buffer without apyrase or $\mathrm{PGE}_{1}$. Platelets were activated with ADP (final concentrations 0, 1.25, 2.5, 5, 10, and $20 \mu \mathrm{M}$ ) for 30 minutes at room temperature, fixed, and analyzed for surface P-selectin expression using flow cytometry. ${ }^{22}$ Platelets were identified by light scatter characteristics and the binding of an FITC-conjugated CD61-specific monoclonal antibody (Y251; DAKO). Nonspecific binding was determined using isotype-matched RPE-conjugated $\mathrm{MIgG}_{2 \mathrm{a}}$ (DAKO), and the expression of P-selectin on platelets was then quantified by the binding of PE-conjugated anti-CD62P monoclonal antibody (1E3; DAKO) to the platelet surface. For each agonist concentration, platelet mean $\mathrm{P}$-selectin fluorescence and percentage of platelets positive for P-selectin expression were compared between CF patients and healthy controls by unpaired $t$ tests.

\section{Ibuprofen and $\mathrm{PGE}_{1}$ inhibition of $\mathrm{CF}$ platelet activation}

Citrated whole blood from CF patients and healthy donor controls $(n=7)$ was preincubated ex vivo with and without $\mathrm{PGE}_{1}(100 \mathrm{nM}$ and $1 \mu \mathrm{M})$. The samples were then activated with $20 \mu \mathrm{M}$ TRAP or $20 \mu \mathrm{M}$ ADP. In other experiments, whole blood $(\mathrm{n}=5)$ was preincubated with $50 \mu \mathrm{g} / \mathrm{mL}$ ibuprofen and stimulated with TRAP and ADP, $20 \mu \mathrm{M}$ U46619 (TXA $_{2}$ analog), or $250 \mu \mathrm{g} / \mathrm{mL}$ AA. Both ibuprofen- and $\mathrm{PGE}_{1}$-treated samples were analyzed for P-selectin expression as with washed platelets.

\section{Measurement of platelet arachidonic acid release and thromboxane $A_{2}$ production}

Washed platelets from $\mathrm{CF}(\mathrm{n}=4)$ and healthy donor $(\mathrm{n}=4)$ blood were labeled with $\left[{ }^{3} \mathrm{H}\right]$-arachidonic acid $\left(0.5 \mu \mathrm{Ci}[0.0185 \mathrm{MBq}] / 2 \times 10^{9}\right.$ platelets $/ \mathrm{mL}, 65.9 \mathrm{Ci}$ [2.4 MBq]/mmol; Perkin Elmer Life and Analytical Sciences, Boston, MA) as previously described. ${ }^{26}$ Platelet samples were resuspended in HEPES-Tyrode buffer, $\mathrm{pH} 7.4$, and stimulated for 2 minutes with buffer or TRAP $(20 \mu \mathrm{M})$, and the supernatants were mixed with butylated hydroxytoluene (BHT) $(50 \mathrm{mg} / \mathrm{mL}$, $3 \mu \mathrm{L} \mathrm{BHT} / 400 \mu \mathrm{L}$ sample) and citric acid (1 M, $60 \mu \mathrm{L} /$ sample), then frozen until analysis. Lipids were extracted and analyzed by thin-layer chromatography with $\mathrm{TXB}_{2}(10 \mu \mathrm{L}$ of $1 \mathrm{mg} / \mathrm{mL}$ stock in ethanol) (Biomol International, Plymouth Meeting, PA) as a standard. ${ }^{27}$

\section{Analysis of platelets for CFTR protein and mRNA}

The expression of the CFTR protein in platelets and platelet membranes was determined by Western blot analysis. Washed platelets from both CF patients $(n=2)$ and healthy control subjects $(n=2)$ were prepared with and without cell surface biotinylation. The blots were incubated with anti-CFTR antibodies (M3A7 and L12B4; Upstate Biotechnology, Lake Placid, NY) and developed. ${ }^{28}$ Canine cocker-spaniel kidney cells (MDCK-1) were used as a positive control. The presence or absence of CFTR mRNA in platelets (and in the positive controls [leukocytes]) was determined by reverse-transcriptase-polymerase chain reaction (RT-PCR), using established methods. ${ }^{29}$ Total RNA was isolated and DNase treated before reverse transcription. ${ }^{30}$ Message from 2 control housekeeping genes (GADPH and $\beta$-actin) was analyzed by real-time RT-PCR using reagent kits obtained from Applied Biosystems (Foster City, CA).

\section{Fatty acid analysis}

Washed platelet pellets were obtained from CF patients $(n=11)$ and healthy control subjects $(n=10)$. Lipid fractions of platelets were extracted and methylated according to the method of Moser and Moser. ${ }^{31}$ Fatty acid methyl esters were quantified via gas chromatography-mass spectrometry as previously described. ${ }^{18}$ Total ion monitoring was performed and the mass of fatty acids was determined by comparing areas of unknown fatty acid methyl esters with a fixed concentration of internal standards. All specimens were analyzed in a blinded fashion and assay batches included platelet lipids from both study groups. The concentrations of fatty acids between CF and healthy controls were compared by unpaired $t$ tests.

\section{Statistics}

Statistical comparisons were made using paired or unpaired $t$ tests as appropriate. Matched comparisons (eg, before and after agonist on the same patient, normal blood with or without CF plasma added) were made using paired $t$ tests. Unmatched comparisons were made using unpaired $t$ tests.

\section{Results}

\section{Circulating activated platelets and platelet reactivity in CF}

CF patients had increased circulating activated platelets compared with healthy controls, as measured by both monocyte-platelet aggregates and neutrophil-platelet aggregates (Figure 1A-B "no agonist"). Platelet activation, as determined by monocyte-platelet aggregates and neutrophil-platelet aggregates, was greater in $\mathrm{CF}$ patients compared with healthy subjects following stimulation with $1.5 \mu \mathrm{M}$ TRAP, $0.5 \mu \mathrm{M}$ ADP, and $20 \mu \mathrm{M}$ ADP (Figure 1). 

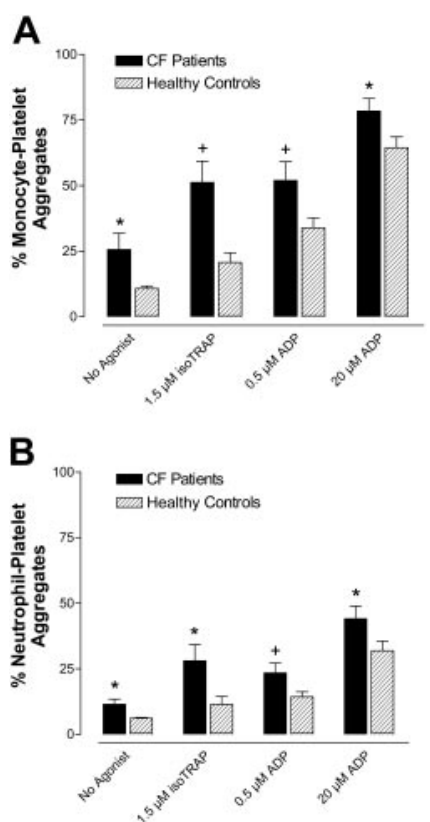

Figure 1. CF patients have increased circulating monocyte- and neutrophilplatelet aggregates and increased platelet responsiveness to ADP and TRAP compared with healthy controls. Whole blood from CF patients and healthy controls was incubated with or without agonist and analyzed for (A) monocyte-platelet aggregates and (B) neutrophil-platelet aggregates. Data are mean $\pm S E M ; n=18$. ${ }^{\star} P<.05$ versus healthy controls. ${ }^{+} P<.01$ versus healthy controls.

\section{Extrinsic versus intrinsic platelet defect}

Monocyte-platelet and neutrophil-platelet aggregates in CF whole blood were higher after incubation with $\mathrm{ABO} / \mathrm{RhD}$-matched $\mathrm{CF}$ plasma than after incubation with normal plasma (Figure 2A). Similarly, monocyteplatelet and neutrophil-platelet aggregates in normal whole blood were higher after incubation with $\mathrm{ABO} / \mathrm{RhD}-$ matched $\mathrm{CF}$ plasma than after incubation with normal plasma (Figure 2B). Figure 2C compares the solid bars of Figure 2A (CF plasma + CF whole blood) with the open bars of Figure $2 \mathrm{~B}$ ( $\mathrm{CF}$ plasma + normal whole blood). Figure $2 \mathrm{C}$ demonstrates that when whole blood from $\mathrm{CF}$ and healthy subjects was incubated in CF plasma, platelet activation (as determined by monocyteplatelet aggregates and neutrophil-platelet aggregates) was greater in $\mathrm{CF}$ blood than in normal blood. In summary, Figure 2 demonstrates that $\mathrm{CF}$ plasma makes normal and $\mathrm{CF}$ platelets more reactive than does normal plasma (Figure 2A-B), but that $\mathrm{CF}$ platelets are more reactive than control platelets irrespective of the plasma milieu (Figure 2C).

In whole blood from healthy control subjects, monocyte- and neutrophil-platelet aggregates were greater when incubated with $\mathrm{ABO} / \mathrm{RhD}$-matched $\mathrm{CF}$ plasma than when incubated with normal plasma, after stimulation with $4 \mu \mathrm{M}$ ADP, $20 \mu \mathrm{M}$ ADP, and $3 \mu \mathrm{M}$ TRAP (Figure 3A).

Similarly, in CF whole blood, monocyte- and neutrophilplatelet aggregates were greater when incubated with $\mathrm{CF}$ plasma than when incubated with $\mathrm{ABO} / \mathrm{RhD}$-matched normal plasma, after stimulation with $4 \mu \mathrm{M}$ ADP, $20 \mu \mathrm{M}$ ADP, and $3 \mu \mathrm{M}$ TRAP (Figure $3 \mathrm{~B})$. Thus, CF plasma increased the reactivity of both normal and CF platelets to ADP and TRAP.

$\mathrm{P}$-selectin expression of washed platelets was greater in $\mathrm{CF}$ patients than in healthy control subjects after activation with various concentrations of ADP (Figure 4). Unstimulated P-selectin expression was slightly, though not significantly, greater in $\mathrm{CF}$ platelets than controls (Figure 4). That washed, plasma-free $\mathrm{CF}$ platelets were more reactive to ADP than normal platelets indicates that the hyperreactivity of CF platelets is due in part to an intrinsic platelet mechanism.

\section{Effects of PGE}

The elevated P-selectin expression after agonist stimulation of $\mathrm{CF}$ platelets was incompletely inhibited by $100 \mathrm{nM} \mathrm{PGE}$ (Figure 5, solid bars). In contrast, normal platelets showed more complete inhibition of agonist-induced P-selectin expression with $\mathrm{PGE}_{1}$ (Figure 5 hatched bars). There was no greater inhibition of P-selectin expression even when using concentrations of $\mathrm{PGE}_{1}$ up to $1 \mu \mathrm{M}$. These results suggest that both increased cyclic adenosine monophosphate (cAMP) levels and other factors are important in the increased platelet surface $\mathrm{P}$-selectin expression in $\mathrm{CF}$.

\section{Effect of ibuprofen on CF platelet function}

Pretreatment of CF platelets with $50 \mu \mathrm{g} / \mathrm{mL}$ ibuprofen did not significantly decrease platelet surface P-selectin expression in response to stimulation with ADP or TRAP (data not shown). However, when AA was used as the agonist, pretreatment with ibuprofen markedly inhibited P-selectin expression, as would be expected. The platelet response to the stable TXA $_{2}$ analog U46619 was unaffected by pretreatment with ibuprofen, verifying the presence of normal $\mathrm{TXA}_{2}$ receptors on these cells.

\section{CFTR protein and mRNA are not expressed in platelets}

CFTR protein was not detected in control or CF platelet lysates or biotinylated platelet membrane fractions using Western blot analysis, but was seen in the control MDCK whole-cell lysate. CFTR mRNA was not detected in platelet preparations from healthy controls. CFTR message was detected in the leukocyte-positive control samples as expected. The mRNA of 2 housekeeping genes
A

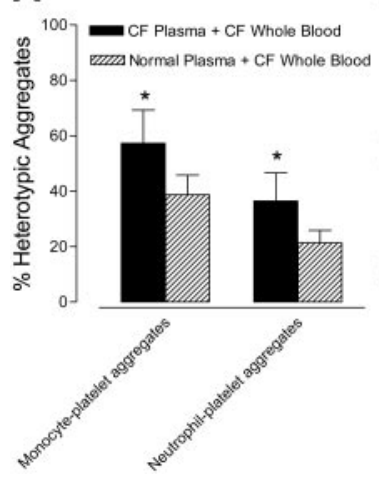

B

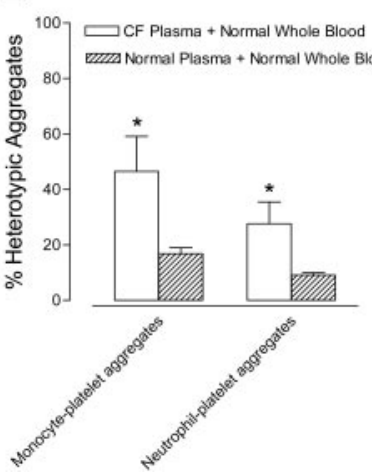

C

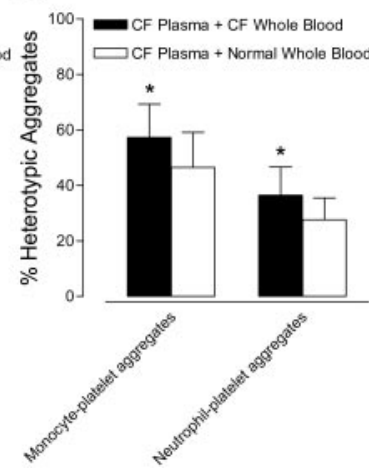

Figure 2. CF plasma causes activation of normal and CF platelets. (A) Monocyte- and neutrophil-platelet aggregates in CF whole blood after incubation in $\mathrm{ABO} / \mathrm{RhD}$ matched CF or normal control plasma. (B) Monocyteand neutrophil-platelet aggregates in normal whole blood after incubation in $\mathrm{ABO} / \mathrm{RhD}$-matched $\mathrm{CF}$ or normal control plasma. (C) Comparison of the solid bars of panel $\mathrm{A}$ (CF plasma + CF whole blood) with the open bars of panel B (CF plasma + normal whole blood). Panel C demonstrates that when whole blood from CF and healthy subjects was incubated in CF plasma, platelet activation (as determined by monocyte-platelet and neutrophilplatelet aggregates) was greater in CF blood than in normal blood. Data are mean \pm SEM; $\mathrm{n}=6 .{ }^{*} P<.05$ versus normal plasma or whole blood. 

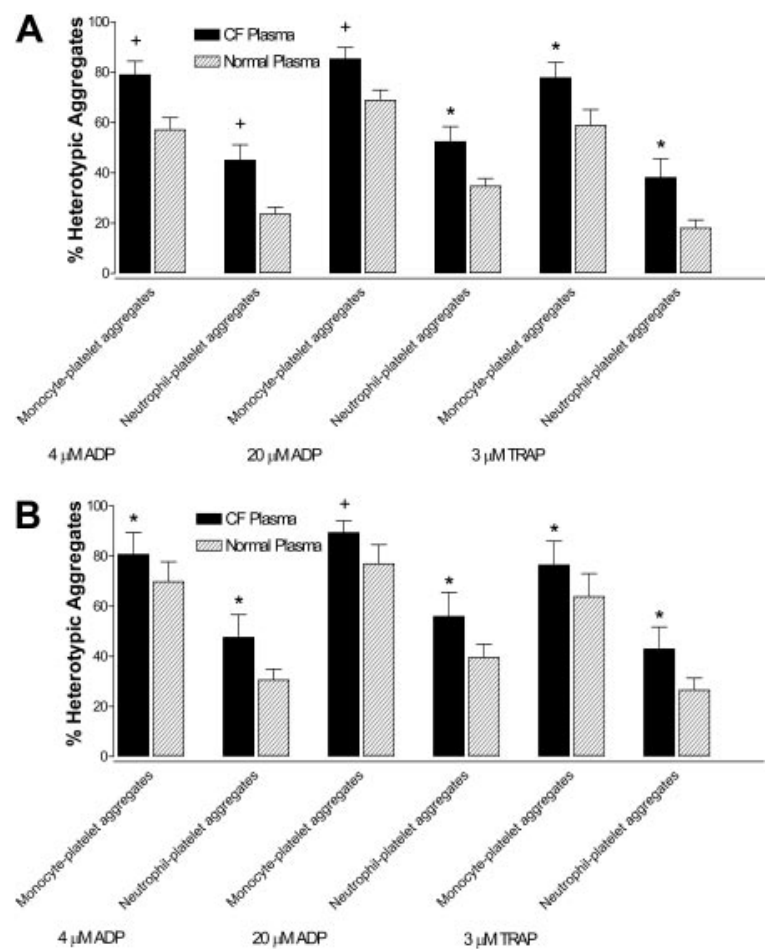

Figure 3. CF plasma increases the reactivity of normal and CF platelets to ADP and TRAP. (A) Monocyte- and neutrophil-platelet aggregates in normal control whole blood incubated with CF plasma or ABO/RhD-matched normal plasma and then stimulated with agonist. (B) Monocyte- and neutrophil-platelet aggregates in CF whole blood incubated with CF plasma or $\mathrm{ABO} / \mathrm{RhD}$-matched normal plasma and then stimulated with agonist. Data are mean \pm SEM; $n=6 .{ }^{\star} P<.05$ versus normal plasma. ${ }^{+} P<.01$ versus normal plasma.

(GADPH and $\beta$-actin) was detected in all platelet samples, confirming the integrity of the platelet RNA.

\section{Platelet fatty acid content}

Analysis of washed platelet pellets for fatty acid pools showed a significant increase in 20:3 n-9 (Mead acid) levels in CF platelets compared with healthy control subject platelets $(P=.017$, Figure $6)$ and plasma $(P=.006$, not shown). There was also an increase in 22:5 n-6 in CF platelets compared with healthy controls $(P=.012)$ (Figure 6). However, CF platelets were not significantly different from control platelets with regard to concentrations of AA (20:4 n-6), DHA (22:6 n-3), and the AA/DHA ratio (Figure 6).

\section{Arachidonic acid release and Mead acid effect}

Not only was total AA not different between CF and control platelets (Figure 6), there was no difference in AA release or synthesis of the AA metabolite $\mathrm{TXA}_{2}$ as demonstrated by use of $\left[{ }^{3} \mathrm{H}\right]$-AA (results not shown). Addition of Mead acid (20:3, n-9) to

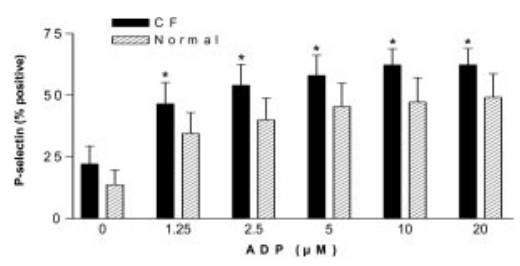

Figure 4. Washed CF platelets are more reactive to ADP than normal platelets as measured by P-selectin expression. Percentage of CF and normal washed platelets expressing $P$-selectin with and without stimulation by ADP. Data are mean \pm $\mathrm{SEM} ; \mathrm{n}=4 .{ }^{*} P<.05$ versus normal platelets.
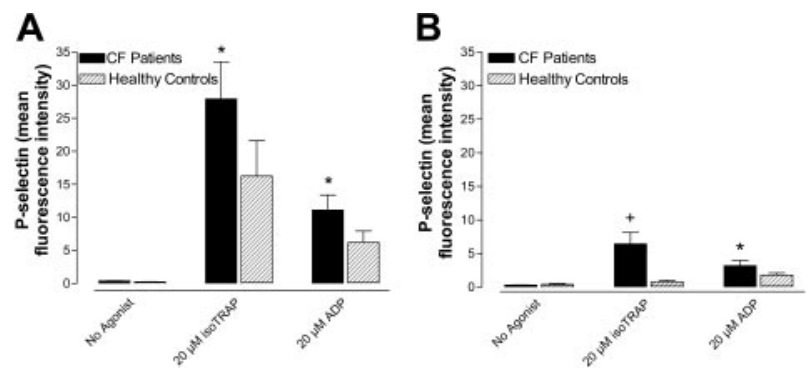

Figure 5. CF platelet hyperreactivity is incompletely inhibited by $\mathrm{PGE}_{1}$. Percentage of $C F$ and normal platelets in whole blood expressing $P$-selectin after stimulation with TRAP or ADP in the absence (A) or presence (B) of $100 \mathrm{nM} \mathrm{PGE}_{1}$. Data are mean $\pm \mathrm{SEM} ; \mathrm{n}=7$. ${ }^{*} P<.05$ versus healthy controls. ${ }^{+} P<.01$ versus healthy controls.

normal platelets did not increase the formation of monocyteplatelet or neutrophil-platelet aggregates (results not shown).

\section{No correlation between platelet activation and vitamin E status or pulmonary function}

There was no correlation between any of the measurements of platelet activation and vitamin E status or pulmonary function as measured by the percent of predicted forced expiratory volume in the first second of expiration $\left(\mathrm{FEV}_{1} \%\right)$ in the $\mathrm{CF}$ patients.

\section{Discussion}

The conclusions of this study are (1) CF patients have an increase in circulating activated platelets and platelet reactivity, as determined by monocyte-platelet aggregation, neutrophil-platelet aggregation, and platelet surface P-selectin; (2) this increased platelet activation in $\mathrm{CF}$ is the result of both a plasma factor(s) and an intrinsic platelet mechanism via cAMP/adenylate cyclase (as evidenced by the results with $\mathrm{PGE}_{1}$ ), but not via platelet CFTR.

In this study, we demonstrated that $\mathrm{CF}$ patients have increased numbers of circulating activated platelets compared with healthy control subjects, as measured by monocyte-platelet and neutrophil-platelet aggregates (Figure 1). We have previously demonstrated that these heterotypic aggregates are very sensitive markers of platelet activation. ${ }^{32}$ In addition, whole blood studies showed that CF platelets had greater aggregability with monocytes and neutrophils in response to agonists than did control platelets (Figure 1). CF plasma caused activation of normal and CF platelets (Figure 2), but the activation was greater in the $\mathrm{CF}$ platelets than in normal platelets. CF plasma also increased the reactivity of normal and CF platelets to ADP and TRAP (Figure 3). Furthermore, there was an increased surface expression of P-selectin in $\mathrm{CF}$ washed platelet preparations compared with washed normal platelets (Figure 4). Taken together, these experiments demonstrate that the increased platelet activation in $\mathrm{CF}$ is the result of both an intrinsic platelet mechanism and plasma factors. Even in well, young CF patients with normal pulmonary function there is an abnormality in platelet function. Our findings are consistent with previous work that has shown increased platelet aggregation and/or markers of platelet activation in $\mathrm{CF}$ patients. ${ }^{10-12,33-35}$ Thus, excessive platelet activation is present in $\mathrm{CF}$ and may contribute significantly to the lung disease seen in this disorder.

Interestingly, our results do not support the earlier findings of increased $\mathrm{TXA}_{2}$ release from CF platelets. ${ }^{10}$ The finding of increased urinary $\mathrm{TXB}_{2}$ by Ciabattoni et all ${ }^{11}$ would support a hypothesis that platelet activation contributes directly to lung damage. The results of our study suggest that there is a source other than platelets for the urinary thromboxane, as has been previously suggested. ${ }^{36}$ However, we did 
A

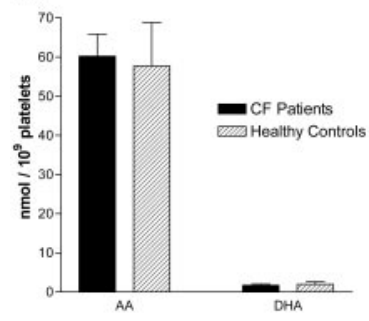

B

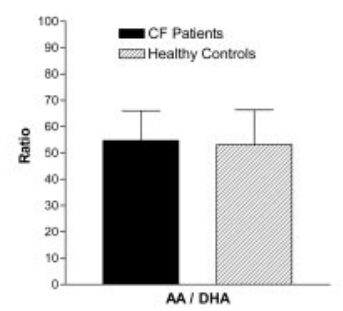

C

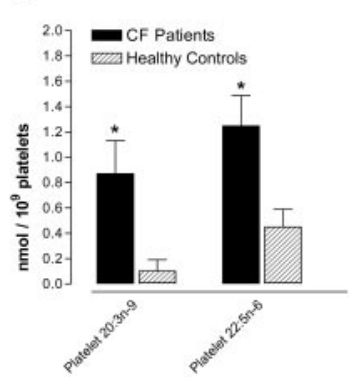

Figure 6. Platelet fatty acid content. There is no difference between $C F$ and control platelets with regard to $\mathrm{AA}, \mathrm{DHA}$, or their ratio (A-B); however, CF platelets have increased Mead acid (20:3 n-9) and 22:5n-6 fatty acid concentrations compared with control platelets (C). Data are mean \pm SEM; $n=11$ CF patients and $n=10$ healthy controls. ${ }^{*} P<.05$ versus control platelets. confirm that the platelets from CF patients are hyperreactive compared with control platelets. The metabolic basis and downstream consequences of the platelet hyperreactivity remain to be elucidated.

Others ${ }^{13,14}$ have shown an incomplete inhibition of platelet aggregation by $\mathrm{PGE}_{1}$, and we observed a decreased response to $\mathrm{PGE}_{1}$ inhibition of surface P-selectin expression in CF compared with control platelets. An absence of the cAMP-regulated chloride channel, CFTR, in CF platelets could explain these findings. However, we found neither message for CFTR nor CFTR protein itself in normal donor platelets. Therefore, the intrinsic abnormality in $\mathrm{CF}$ platelets must be due to a non-CFTR cAMP-regulated platelet chloride channel or to a CFTR-related abnormality that is expressed in megakaryocytes but not in platelets.

We have reported abnormalities in fatty acids in CFTR expressing tissue that could affect inflammation in CF patients; that is, epithelial cells have an abnormal ratio of omega- 6 to omega- 3 fatty acids, specifically an increase in the AA/DHA ratio. ${ }^{18}$ Such an imbalance could lead to an increase in proinflammatory derivatives of AA and a paucity of anti-inflammatory DHA metabolites.$^{37}$ Consistent with our inability to find evidence of CFTR expression in platelets, however, platelets from CF patients did not differ significantly from control platelets with regard to AA or DHA (Figure 6). Thus, we cannot ascribe the increased intrinsic platelet reactivity in $\mathrm{CF}$ to an abnormality in platelet AA/DHA balance. However, this imbalance is present in plasma ${ }^{18,38}$ and could lead to platelet activation from increased circulating AA metabolites (consistent with the previously reported increased urinary thromboxane in $\mathrm{CF}^{11}$ ). Recently, $\mathrm{CF}$ patients and $\mathrm{CF}$ knock-out mice have been shown to be deficient in the anti-inflammatory lipoxin family of mediators. ${ }^{39}$ The proposed imbalance in CF pro- and anti-inflammatory mediators could favor platelet activation, even if the platelets themselves do not intrinsically release excess thromboxane.

Further fatty acid analysis revealed an increase in the terminal n-6 fatty acid (22:5 n-6) in CF platelets (Figure 6). Accumulation of this long-chain, polyunsaturated fatty acid may competitively inhibit the generation of DHA at the level of the DHA precursor, 22:5 n-3. We also observed an increase in Mead acid (20:3 n-9) in CF platelets (Figure 6) and plasma (not shown). Lagarde et $\mathrm{al}^{40}$ showed that Mead acid is metabolized by a platelet-derived lipoxygenase to an end product with $\mathrm{PGE}_{2}$-like activity that enhances platelet aggregation and that loading normal platelets with Mead acid enhances their aggregability. ${ }^{41}$ However, when we incubated platelets with 3 different concentrations of Mead acid in the presence or absence of a platelet agonist, we did not observe any increase in whole blood heterotypic aggregates. In summary, an intrinsic fatty acid abnormality is present in CF platelets and it is possible that the increase in platelet activation observed is due to a manifestation of this abnormality, but excess Mead acid alone does not lead to increased platelet-leukocyte aggregates.

There are a number of potential plasma-mediated explanations for platelet hyperreactivity in CF. The imbalance in omega-3 and omega- 6 fatty acids seen in CF serum may favor inflammation, as may an increase in plasma levels of sCD40L. ${ }^{34}$ In addition, approximately $90 \%$ of $\mathrm{CF}$ patients have pancreatic insufficiency and are at risk for malabsorption of fat-soluble vitamins, ${ }^{9}$ leading some to postulate a relationship between low levels of the antioxidant vitamin $\mathrm{E}$ and increased platelet activation. ${ }^{11,33}$ Our results do not support the concept that increased platelet activation in $\mathrm{CF}$ is a consequence of a nutritional depletion of vitamin $\mathrm{E}$, as we saw no correlation between vitamin $\mathrm{E}$ status and platelet activation. There are other oxidant stresses in CF (including a purported depletion of glutathione, an increase in reactive oxygen species from neutrophils, and generation of isoprostanes from long-chain polyunsaturated fatty acids by the action of $\left.\mathrm{H}_{2} \mathrm{O}_{2}\right)^{42,43}$ that may contribute to platelet activation.

CFTR dysfunction, as seen in CF, has been associated with an elevation in plasma ATP. ${ }^{44}$ On balance, ATP is probably an agonist of platelet aggregation and activation in vivo. ${ }^{45}$ Thus, increased platelet activation may be a direct consequence of the basic molecular defect in CFTR due to disturbances in fatty acid metabolism or due to increased plasma ATP concentrations even though CFTR is not expressed in platelets.

The pulmonary inflammatory response in CF patients is exaggerated compared with healthy individuals, with evidence of airway inflammation as early as 4 weeks of age. ${ }^{46}$ Konstan et al ${ }^{17}$ showed that high-dose ibuprofen led to a slowing of the loss of lung function when used over 4 years in CF patients. Serum levels of ibuprofen in this study were high enough to inhibit the migration, adherence, swelling, and aggregation of neutrophils. ${ }^{17,47}$ Many CF clinicians have avoided using such high doses of ibuprofen because of the need to monitor serum levels of the drug and because of concerns about the potential adverse effects of this high-dose regimen. Thus, in 2003 only about $5 \%$ of patients cared for at $\mathrm{CF}$ Foundation-accredited centers received high-dose ibuprofen. ${ }^{9}$ If the benefit observed in the NSAID study of CF patients was due, even in part, to inhibition of platelet activation rather than decreased neutrophil function, then a lower dose regimen of NSAID might be effective and would be more appealing to clinicians and patients. Furthermore, aspirin and/or clopidogrel, which are stronger antiplatelet drugs than NSAIDs, may have greater beneficial effects than NSAIDs in patients with CF.

\section{Acknowledgments}

We thank Bruce Stanton, PhD, and Bonnie Courtemarsh (Dartmouth Medical School) for performing Western blot analysis of platelets for CFTR protein; Joanne Cluette-Brown (Massachusetts General Hospital) for fatty acid analysis of platelets; and Lori Krueger for assistance in platelet function studies. 
From www.bloodjournal.org at UNIV OF MASSACHUSETTS on April 3, 2008. For personal use only.

\section{References}

1. Gibson RL, Burns JL, Ramsey BW. Pathophysiology and management of pulmonary infections in cystic fibrosis. Am J Respir Crit Care Med. 2003; 168:918-951.

2. Kerem B, Rommens JM, Buchanan JA, et al. Identification of the cystic fibrosis gene: genetic analysis. Science. 1989;245:1073-1080.

3. Riordan JR, Rommens JM, Kerem B, et al. Identification of the cystic fibrosis gene: cloning and characterization of complementary DNA. Science. 1989;245:1066-1073.

4. Rommens JM, lannuzzi MC, Kerem B, et al. Identification of the cystic fibrosis gene: chromosome walking and jumping. Science. 1989;245:10591065.

5. Reisin IL, Prat AG, Abraham EH, et al. The cystic fibrosis transmembrane conductance regulator is a dual ATP and chloride channel. J Biol Chem. 1994;269:20584-20591.

6. Schwiebert EM, Egan ME, Hwang TH, et al. CFTR regulates outwardly rectifying chloride channels through an autocrine mechanism involving ATP. Cell. 1995;81:1063-1073.

7. Stutts MJ, Canessa CM, Olsen JC, et al. CFTR as a cAMP-dependent regulator of sodium channels. Science. 1995;269:847-850.

8. Chernick WW, Barbero GJ. Composition of tracheobronchial secretions in cystic fibrosis of the pancreas and bronchiectasis. Pediatrics. 1959; 24:739-745.

9. 2003 Annual Data Report to the Center Directors. Cystic Fibrosis Foundation Patient Registry. Bethesda, MD; 2004

10. Stead RJ, Barradas MA, Mikhailidis DP, et al. Platelet hyperaggregability in cystic fibrosis. Prostaglandins Leukot Med. 1987;26:91-103.

11. Ciabattoni G, Davi G, Collura M, et al. In vivo lipid peroxidation and platelet activation in cystic fibrosis. Am J Respir Crit Care Med. 2000;162:11951201.

12. Mikhailidis DP, Stead RJ, Barradas MA, Hodson ME, Batten JC, Dandona P. Platelet abnormalities in patients with cystic fibrosis and obligate heterozygotes. Haematologica. 1990;75:137-140.

13. Agam G, Aviram M, Zilberman-Kaufman M, Rothstein A, Livne AA. Cyclic AMP-related and cationaffected human platelet chloride transport regulation. Eur J Clin Chem Clin Biochem. 1995;33: 329-335.

14. Samuels CE, Robinson PG, Elliott RB. Decreased inhibition of platelet aggregation by PGE1 in children with cystic fibrosis and their parents. Prostaglandins. 1975;10:617-621.

15. Klinger MHF. Inflammation. In: Michelson AD, ed. Platelets. San Diego, CA: Academic Press; 2002: 459-467.

16. Yamamoto $H$, Nagata $M$, Tabe $K$, et al. The evidence of platelet activation in bronchial asthma. J Allergy Clin Immunol. 1993;91:79-87.

17. Konstan MW, Byard PJ, Hoppel CL, Davis PB. Effect of high-dose ibuprofen in patients with cystic fibrosis. N Engl J Med. 1995;332:848-854.

18. Freedman SD, Blanco PG, Zaman MM, et al. Association of cystic fibrosis with abnormalities in fatty acid metabolism. N Engl J Med. 2004;350: 560-569.

19. Rosenstein BJ, Cutting GR. The diagnosis of cystic fibrosis: a consensus statement: Cystic Fibrosis Foundation Consensus Panel. J Pediatr. 1998;132:589-595.

20. Barnard MR, Krueger LA, Frelinger LA, Furman MI, Michelson AD. Whole blood analysis of leukocyte-platelet aggregates. In: Robinson JP, Darzynkiewicz Z, Dean PN, et al, eds. Current Protocols in Cytometry. New York, NY: John Wiley \& Sons; 2003:6.15.01-16.15.08.

21. Linden MD, Frelinger LA, Barnard MR, Przyklenk K, Furman MI, Michelson AD. Application of flow cytometry to platelet disorders. Semin Thromb Hemost. 2004;30:501-511.

22. Krueger LA, Barnard MR, Frelinger LA, Furman $\mathrm{MI}$, Michelson AD. Immunophenotypic analysis of platelets. In: Robinson JP, Darzynkiewicz Z, Dean $\mathrm{PN}$, et al, eds. Current Protocols in Cytometry. New York, NY: John Wiley \& Sons; 2002:6.10.01 16.10.17.

23. Michelson AD, Barnard MR, Krueger LA Frelinger LA, Furman MI. Evaluaton of platelet function by flow cytometry. Methods. 2000;21: 259-270.

24. Michelson AD, Barnard MR, Krueger LA, Frelinger LA, Furman MI. Flow Cytometry. In Michelson AD, ed. Platelets. San Diego, CA: Academic Press; 2002:297-315.

25. Michelson AD, Barnard MR, Hechtman HB, et al. In vivo tracking of platelets: circulating degranulated platelets rapidly lose surface P-selectin but continue to circulate and function. Proc Natl Acad Sci U S A. 1996;93:11877-11882.

26. Neufeld EJ, Majerus PW. Arachidonate release and phosphatidic acid turnover in stimulated human platelets. J Biol Chem. 1983;258:2461-2467.

27. Connor AM, Laposata M. A rapid assay for platelet thromboxane production and its use in assessing prior aspirin ingestion. Am J Clin Pathol. 1988; 89:216-221.

28. Moyer BD, Loffing J, Schwiebert EM, et al. Membrane trafficking of the cystic fibrosis gene product, cystic fibrosis transmembrane conductance regulator, tagged with green fluorescent protein in madin-darby canine kidney cells. J Biol Chem. 1998;273:21759-21768.

29. Sambrook J, Fritsch EF, Maniatis T. Molecular Cloning: A Laboratory Manual. 2nd ed. Cold Spring Harbor, NY: Cold Spring Harbor Laboratory Press; 1989

30. Perricone MA, Morris JE, Pavelka K, et al. Aerosol and lobar administration of a recombinant adenovirus to individuals with cystic fibrosis, II: transfection efficiency in airway epithelium. Hum Gene Ther. 2001:12:1383-1394.

31. Moser HW, Moser AB. Measurement of Saturated Very Long Chain Fatty Acids in Plasma: Techniques in Diagnostic Human Biochemical Genetics: A Laboratory Manual. New York, NY: WileyLiss; 1991.

32. Michelson AD, Barnard MR, Krueger LA, Valeri CR, Furman MI. Circulating monocyte-platelet aggregates are a more sensitive marker of in vivo platelet activation than platelet surface P-selectin studies in baboons, human coronary intervention, and human acute myocardial infarction. Circulation. 2001;104:1533-1537.

33. Davis PB, Hubbard VS, Dieckman L, Boat TF, Stern RC, Doershuk CF. Effects of alpha-tocopherol on platelet membrane function in cystic fibrosis. J Lab Clin Med. 1984;104:203-212.

34. Falco A, Romano M, Lapichino L, Collura M, Davi G. Increased soluble CD40 ligand levels in cystic fibrosis. J Thromb Haemost. 2004;2:557-560.

35. Schwarz KB, Rosensweig J, Sharma S, et al. Plasma markers of platelet activation in cystic fibrosis liver and lung disease. J Pediatr Gastroenterol Nutr. 2003;37:187-191.

36. Catella F, FitzGerald GA. Paired analysis of urinary thromboxane B2 metabolites in humans. Thromb Res. 1987; 47:647-656.

37. Serhan CN, Hong S, Gronert K, et al. Resolvins: a family of bioactive products of omega-3 fatty acid transformation circuits initiated by aspirin treatment that counter proinflammation signals. J Exp Med. 2002;196:1025-1037.

38. Strandvik B, Gronowitz E, Enlund F, Martinsson T, Wahlstrom J. Essential fatty acid deficiency in relation to genotype in patients with cystic fibrosis. J Pediatr. 2001;139:650-655.

39. Karp CL, Flick LM, Park KW, et al. Defective lipoxin-mediated anti-inflammatory activity in the cystic fibrosis airway. Nat Immunol. 2004;5:388392.

40. Lagarde M, Burtin M, Rigaud M, Sprecher $H$ Dechavanne M, Renaud S. Prostaglandin E2-like activity of 20:3n-9 platelet lipoxygenase endproduct. FEBS Lett. 1985;181:53-56.

41. Lagarde M, Burtin M, Sprecher $H$, Dechavanne $M$, Renaud S. Potentiating effect of 5,8,11-eicosatrienoic acid on human platelet aggregation. Lipids. 1983;18:291-294.

42. Back El, Frindt C, Nohr D, et al. Antioxidant deficiency in cystic fibrosis: when is the right time to take action? Am J Clin Nutr. 2004;80:374-384.

43. Koehler DR, Downey GP, Sweezey NB, Tanswell $\mathrm{AK}, \mathrm{Hu}$ J. Lung inflammation as a therapuetic target in cystic fibrosis. Am J Respir Cell Mol Biol. 2004;31:377-381.

44. Abraham EH, Sterling KM, Kim RJ, et al. Erythrocyte membrane ATP binding cassette (ABC) proteins: MRP1 and CFTR as well as CD39 (ectoapyrase) involved in RBC ATP transport and elevated blood plasma ATP of cystic fibrosis. Blood Cells Mol Dis. 2001;27:165-180.

45. Birk AV, Broekman MJ, Gladek EM, et al. Role of extracellular ATP metabolism in regulation of platelet reactivity. J Lab Clin Med. 2002;140:166175.

46. Khan TZ, Wagener JS, Bost T, Martinez J, Accurso FJ, Riches DW. Early pulmonary inflammation in infants with cystic fibrosis. Am J Respir Crit Care Med. 1995;151:1075-1082.

47. Konstan MW, Krenicky JE, Finney MR, et al. Effect of ibuprofen on neutrophil migration in vivo in cystic fibrosis and healthy subjects. J Pharmacol Exp Ther. 2003;306:1086-1091. 